\title{
Targeting protein kinases for anti-glioma treatment
}

\author{
Emanuela B. Pucko, Robert P. Ostrowski \\ Department of Experimental and Clinical Neuropathology, Mossakowski Medical Research Centre, Polish Academy of Sciences, \\ Warsaw, Poland
}

\begin{abstract}
The genetic alterations related to many kinases are responsible for the formation of glial tumours. In addition it is the cell kinases that keep the cancerous signalling machinery in motion, thus enabling tumour cell growth, motility and invasion. Kinase inhibitors may have a potential to surpass the classical oncolytic treatment for gliomas. However, overcoming drug resistance mechanisms and limited blood-brain barrier (BBB) permeability are the remaining daunting issues. Latest research explores novel kinase inhibitors, yielding several promising results, including those from CK2 inhibition studies, as well as the possibility of relabelling the inhibitors previously approved for tumours other than glial tumours.
\end{abstract}

Key words: glioblastoma, SEGA, protein kinase inhibitors, CK2, isothioureas.

\section{Introduction}

Tumours of glial origin constitute the largest group of primary neoplasms of the central nervous system (CNS). Consistently with up-to-date classification of the nervous system tumours, elaborated by the World Health Organization (WHO) in 2016, four grades of histological malignancy have been distinguished for astroglial tumours (grade I-IV) [63,66]. Astrocytomas of grade I malignancy are usually well demarcated from the surrounding tissues and show a slow growth and good prognosis. This group includes subependymal giant cell astrocytoma (SEGA), which is a rare, benign childhood neoplasm of grade I histological malignancy according to the WHO classification (WHO GI). SEGA tumours occur in approximately $10-20 \%$ of patients with tuberous sclerosis complex (TSC), which is a rare genetic condition $[15,82]$.
While astroglial and oligodendroglial tumours, characterized by infiltrative growth and a tendency towards rapid progression, are classed as neoplasms of grade II-IV malignancy. Gliomas of high degree of malignancy show a large resistance to radio- and chemotherapy. For a few recent decades no substantial progress for their treatment has been noted [53].

Primary glioblastoma (GBM) can be characterized by mutations within the genes coding for growth factors activating MAPK and PI3K signalling pathways as well as the mutations inactivating the signalling pathways controlled by RB and TP53 suppressor genes. Here we have the mutation and amplification of the epidermal growth factor receptor (EGFR) gene, homozygous deletion of cyclin-dependent kinase inhibitor 2A (CDKN2A), amplification of the cyclin-dependent kinase 4 (CDK4), or ubiquitin-protein ligase MDM2/E3 or MDM4, the

\section{Communicating author}

Robert Ostrowski, PhD, Dsc, Department of Experimental and Clinical Neuropathology, Mossakowski Medical Research Centre, Polish Academy of Sciences, 5 Pawińskiego St., 02-106 Warsaw, Poland, e-mail: rostrowski@imdik.pan.pl 
inhibitor of p53 transcriptional activation, as well as the mutation/homozygous deletion in RB1 or PTEN mutation $[10,73]$.

Malignant gliomas show the overexpression of growth factors and proteins associated with processes of migration and angiogenesis. It has been revealed that glioblastoma is the tumour of high molecular heterogeneity, which determines the classification system, prognosis and therapeutic decisions [2]. The molecular progression of gliomas is associated with the accumulation of genetic and epigenetic alterations [3], including the above mentioned loss of suppressor gene function (PTEN, TP53, $C D K N 2 A, R B)$ or the activation of oncogenic signalling pathways [19]. The most recent WHO 2016 classification introduces molecular parameters for the diagnostics and prognosis of malignant gliomas. The mutation within the genes coding for isocitrate dehydrogenases $I D H 1$ or $I D H 2$ is of basic relevance in this regard. Diffuse gliomas, showing $I D H 1 / 2$ mutation, have a better prognosis than that for glial tumours without such mutation. In about $90 \%$ of cases, GBM occurs de novo, as a primary malignant glioma without IDH1/2 mutation, so called IDH-wildtype primary glioblastoma. The determination of the molecular signatures may be applicable in clinical diagnostics and prognosis [72].

Secondary glioblastomas develop from astrocytoma of grade II or III malignancy $[2,79]$. IDH-mutant secondary glioblastomas are characterized by a mutation of IDH1/2 genes, mutations within PTEN, $E G F R$, and TP53 genes, and the loss of heterozygosity on chromosome 10, hypermethylation of $R B 1$ gene promoter as well as the amplification or overexpression of PDGF [4].

The issue of gliomas resistant to therapy, similar to other types of tumours, should be analysed at the molecular level. Currently used treatment, including surgery, radiotherapy and temozolomide chemotherapy, increased the median survival merely by a few months. In addition, these treatment options have significant limitations. It is known that diffuse gliomas are not curable by surgical resection. Moreover, radiotherapy and anticancer agents oftentimes are lethal to normal cells as well. Therefore, it is mandatory to search for more novel tumour cell-specific anticancer agents, with different mechanisms of action and higher therapeutic efficacy. Kinase inhibition appears as one of the increasingly studied approach in this regard [50]. There is a reliance of cancer cells on the oncogenic kinases which hence should be considered as a target for treatment.

We reviewed past and current developments in the kinase inhibition as a therapeutic approach for tumours of glial origin. Searched databases included PubMed and ISI Web of Knowledge for the last twenty years. Search terms included "kinase inhibitor", "glioblastoma", "glioma", "SEGA" and those denoting particular kinases and molecular pathways.

Eight major groups of human kinases were taken into account and those the inhibition of which has been successfully attempted are subject of this review $[37,50]$. However, the subdivisions of this review reflect rather the oncogenic pathways with crucial involvement of kinases as well as their inhibition as a therapeutic strategy for gliomas.

\section{Results and discussion \\ $\mathrm{PI3K} / \mathrm{Akt} / \mathrm{mTOR}$ pathway}

The mTOR pathway is frequently activated in subependymal giant cell astrocytoma (SEGA; subependymal and cortical tubers) that, together with neoplasms of internal organs, belongs to the tuberous sclerosis complex [93]. TSC is associated with a mutation of one of the two suppressor genes: TSC1 or TSC2 [58]. The TSC1 gene is coding for the protein called hamartin, while the TSC2 gene codes for tuberin. Both proteins form the TSC1/TSC2 complex, which activates GTP-ase and inhibits the activity of mTOR signalling pathway [31]. The cessation of the activity of tuberin-hamartin complex stimulates the activation of the mTOR pathway and the phosphorylation of protein kinase S6K. The mTOR kinase is a serine-threonine kinase that integrates the signals regulating a multitude of cellular processes such as growth and cell cycle regulation, as well as the process of translation through the aforementioned ribosomal protein 56 kinases (S6Ks) [77]. Both surgical methods and pharmacological therapy, including mTOR inhibitors, are being used for SEGA treatment $[43,48,82]$. The inhibitors of the mTOR pathway (rapamycin and its derivatives - temsirolimus and everolimus) have a proven clinical efficacy in oncology and are indicated for the treatment of patients with SEGA, who do not qualify for surgical treatment $[38,96]$.

Due to the fact that both surgical treatment and therapies aimed at the inhibition of the MTOR pathway are not free of risk of tumour regrowth, 
the search for alternative therapeutic solutions is reasonable. The inhibitors of casein kinase 2 (CK2), which can participate in the modulation of cancer signalling pathways, including mTOR-related ones, appears to be an interesting group of agents in this regard [81]. Recent studies have shown that CK2 inhibitor 4,5,6,7-tetrabromo-1H-benzimidazole (TBI) reduced the number and viability of SEGA cells derived from a paediatric case of TSC [87].

In turn, glioblastoma can be characterized by a high proliferating activity of neoplastic cells as well as the remarkable invasiveness and enhanced angiogenesis, due to dysregulation of numerous signalling pathways. These disturbances most often involve the two most important signalling cascades of the PI3K/Akt/mTOR and Ras/MEK/MAPK pathways, which play a key role in cell proliferation $[1,76]$.

The first component of the intracellular complex of the PI3K-PTEN-Akt-mTOR signalling pathway is phosphatidyl-inositol 3-kinase (PI3K), which belongs to the intracellular lipid kinase family, regulating the proliferation, differentiation, metabolism and survivability of cells [40]. Hyperactivity of PI3K/ AKT/mTOR pathway in GBM is caused by numerous genetic abnormalities including overexpression of receptor tyrosine kinase (RTK) such as EGFR, ErbB2, PDGFRA or MET [18]. The amplification of the EGFR gene causes the excessive activation of PI3K in approximately $45 \%$ of GBM cases [83]. The active $\mathrm{PI3K}$ catalyses the conversion of phospatidyl-inositol-4,5-diphosphate (PIP2) to phospatidyl-inositol-3,4,5-triphosphate (PIP3) [22], what can be negatively regulated by PTEN (phosphatase and tensin homolog on chromosome ten). Unfortunately, the PTEN mutation is a genetic trait in $50 \%$ of patients with GBM and the loss of PTEN function highly correlates with the activation of AKT. In addition, the increased PIP3 production stimulates the translocation of AKT and the phosphoinositide-dependent protein kinase-1 (PDK1) to the cell membrane. The active AKT activates mTORC1 though phosphorylation that inhibits the action of TSC2, which together with TSC1 negatively regulate $\mathrm{mTORC} 1$. As a consequence, TSC1/TSC2 stops inhibiting the activity of Rheb protein (Ras homolog enriched in the brain) that binds GTP [45]. The mTORC1 kinase is an important effector of PI3K and possesses two substrates: p70S6K1 kinase (later called S6K1), which plays a substantial role in the formation of malignant glioma, and the 4E-BP1 protein, which together with S6K1 kinase participates in protein synthesis [65]. The mTORC2 is activated by PI3K, to contribute to the Akt kinase phosphorylation as well as SGK1 and PKC $\alpha$ activation. All mTORC2 activated kinases play an important role in the regulation of cell proliferation and growth [1]. It seems that inhibiting the above kinases might provide the effective antitumor strategy. However, the first generation of PI3K inhibitors, represented by wortmannin and LY294002, with a documented antitumor effect in the in vivo and in vitro studies, turned out to be highly toxic [76]. In turn, perifosine appears to be a promising inhibitor of AKT kinase, by disrupting the translocation of AKT to the cell membrane, thus resulting in the inhibition of kinase phosphorylation and activation [42]. Unfortunately, in case of gliomas this inhibitor can occur hardly effective due to limited capabilities of crossing the blood-brain barrier. The further step of the PI3K/AKT pathway is the activation of mTOR kinase, however its inhibitors, mostly rapamycin (sirolimus) and the analogues everolimus and temsirolimus showed a limited effectiveness in the clinical studies of malignant glioma, which can result from feedback loops and the involvement of other signalling pathways [9]. Interestingly, it has been revealed that a common anti-diabetic agent metformin may reduce tumour expansion via inhibiting mTOR [61].

The inhibition of protein (and lipid) kinase pathways may occur necessary in order to overcome the resistance to molecular targeted therapies [46]. Epidermal growth factor receptor with tyrosine kinase activity is one of therapeutic targets that may have significance in the treatment of patients with GBM. Overexpression or amplification of the EGFR gene occurs in about $40-50 \%$ of patients with gliomas. However, the EGFR tyrosine kinase inhibition studies (erlotinib and gefitinib) brought clinically a failure regarding their anticancer effect [113]. Supposedly the therapeutic failures associated with EGFR inhibition can be linked to the activation of the $\mathrm{PI3K} / \mathrm{AKT} / \mathrm{mTOR}$ pathway in the cells escaping the therapy [27]. Preclinical research has however shown that EGFR inhibition combined with the inhibition of other pathways including PI3K, CK2, and JAK2 may potentially prevent drug resistance $[25,101,122]$. More new studies emerge that investigate combined therapies as a remedy to overcome resistance to kinase inhibitors within multiple tumorigenic pathways [11,64]. 


\section{Ras/MEK/MAPK pathway}

In patients with malignant glioma, the mitogenic signalling pathway of mitogen-activated protein kinases (MAPKs) becomes activated due to the loss of fibromin and Ras protein activation [83]. Ras/ Raf/MEK1/2/ERK1/2 signalling pathways are being put into effect as a result of RTK action. Ras protein activates serine/threonine Raf kinase, which in turn activates MEK1/2, leading to the activation of ERK1/2, which may phosphorylate TSC2. As a result it leads to the activation of mTOR and the enhancement of translation of proteins involved in cell proliferation, especially transcription factors. According to "The Cancer Genome Atlas", in $86 \%$ of gliomas, at least one genetic alteration affects Ras/Raf/ERK1/2 [22]. Highly selective inhibitors (vemurafenib, dabrafenib) of serine/threonine-protein kinase B-Raf (BRAF) have been already approved by the FDA for melanoma treatment $[52,70]$. It has been also postulated that RAF inhibitors and/or MEK inhibitors (trametinib) can be considered for the treatment of BRAF-altered glioma, especially regarding paediatric and adult astrocytomas [100]. Kinases of the MAPK family, ERK, p38 and JNK, play a well-documented tumorigenic role in GBM. ERK1/2 participates in the migration and invasion of U87MG cells, as determined with the use of ERK1/2 inhibitor PD98059 [59]. This kinase has been also demonstrated to mediate the adhesion of glioma cells to the components of ECM, while this effect was opposed when PD98059 or U0126 were administered [90]. ERK1/2 signalling also participates in the invasion and stemness of GBM cells derived from human surgical specimens; these effects were verified by using SCH772984, the specific inhibitor of ERK1/2 [129]. On the other hand, the sulphoraphane-induced, sustained ERK1/2 activation may induce apoptosis in malignant glioma cells, which point towards the involvement of ERK in a stimulus- and time-dependent manner [123]. As for p38 MAPK, it has been postulated to drive glioma invasion, hence the role of p38 inhibition in heightening the vulnerability of glioma to chemotherapy [34]. On the other hand, p38 inhibition can be associated with a decrease in cell death, thus counterbalancing putative anti-tumour effects [105]. In turn, the inhibition of c-Jun N-terminal kinase (JNK) with SP600125 has been revealed to increase the cytotoxic effect of TMZ via suppression of Akt phosphorylation in U87MG cell line and subsequently suppressed phosphorylation of GSK3- $\beta$ and Bad [118]. In addition, the activity of JNK is required for the maintenance of stem-like glioblastoma cells and their tumour-initiating potential, and the JNK inhibitors (SP600125) have a potential to reduce these properties as well as to deplete these cells population in vivo [67].

\section{Cyclin-dependent kinases}

Cyclin-dependent kinases (CDKs) are involved in the cell cycle and oncogenesis, controlling the G1 restriction point. The CDK4/CDK6-cyclin D1-Rb-p16/ ink4a pathway is frequently dysregulated in glioblastoma [92]. As determined in preclinical research, the CDK4 and CDK6 kinase inhibitor abemaciclib has a potential for treating primary central nervous system tumours including glioblastoma. Administered alone or in the combination with Temozolomide, abemaciclib increased the survival time of intracranial U87MG tumour-bearing rats [91]. Apart from inhibiting CDK4 and CDK6, abemaciclib affects GSK3 $\beta$ and CaMKII, and potently inhibits Rb-wild type GBM cell lines U87MG, DBTRG-05MG, A172, and T98G [16]. Abemaciclib has been approved as a single agent therapy for metastatic breast cancer. Its relatively improved permeability across blood-brain barrier (BBB), and hence capability of targeting glial tumours, still remains to be verified in ongoing clinical studies (NCT02981940) [99]. However, clinical trials with CDK inhibitors palbociclib and ribociclib for gliomas were early terminated due to lack of efficacy $[71,112]$. Besides, CDK4/6 inhibition may also confer therapeutic resistance of GBM with a crucial involvement of c-Met/TrkA-B pathway, as revealed recently [80].

\section{Casein kinase 2}

Casein kinase 2 (CK2) participates in the regulation of several complex cell processes including the activation of numerous signalling pathways such as JAK/STAT, NF-kB, PI3K/Akt, HSP90 as well as it regulates suppressor proteins PTEN, P53 and protooncogenes c-Myc and c-Myb. CK2 overexpression has been documented in neoplasms of the kidneys, head and neck, and the colon. This kinase has thus become a potential therapeutic target and its inhibitors alone or in combination with other compounds, have been proposed as promising pharmaceutical agents for the treatment of different neoplastic growth processes $[28-30,55,60,75,108,125]$. In addi- 
tion, the compounds 2-dimethylamino-4,5,6,7-tetrabromo- $1 \mathrm{H}$-benzimidazole (DMAT) and TBI proved to be not only strong inhibitors of CK2, but also of other kinases such as PIM, DYRKs, HIPK2 and ERK8 [84]. Although CK2 inhibitors show different effectiveness and specificity, nearly all can inhibit cell proliferation and induce caspase-dependent apoptosis in established tumour cell lines [49].

Studies have shown that the compound CX-4945, which is an inhibitor of CK2, suppresses the activation of JAK/STAT, NF-KB and AKT signalling pathways in the glioma cells. Azonaphthalene derivatives, which are selective CK2 inhibitors, cause the cell cycle arrest in the U373 human glioma cell line [74]. Moreover, a decrease in the activity of CK2, induced the cell death via a modulation of MTOR and MAPK signalling pathways in the human glioma cells, thus overcoming their resistance to the routine anticancer drugs.

In the recent years novel inhibitors of protein kinases have come under study. Here we have derivatives of the pentabromobenzyl-isothiourea (under the abbreviated name ZKKs), which show some structural similarity to CK2 inhibitors, such as polybrominated benzimidazoles TBI and DMAT. However, it turned out that despite structural similarity these agents are not specific towards CK2 as the studies with the use of 130 protein kinases panel showed that $\mathrm{N}, \mathrm{N}^{\prime}$-dimethyl-S-(2,3,4,5,6-pentabromobenzyl)-isothiouronium bromide (ZKK-3) at the concentration of $10 \mu \mathrm{M}$ shows over $70 \%$ inhibition of the activity of protein kinases PIM1, PIM3, IGF-1R and IR, taking part in the metabolic pathways of normal and neoplastic cells, including those of glioma [54,55]. The cytotoxic effect of selected isothiourea derivatives has been demonstrated in the cell line of the rat C6 glioma and highly malignant human glioma [49].

Isothioureas act also as inhibitors of the CXCR4 receptor, which, after CXCL12 chemokine binding, may activate PKC and PI3K/AKT pathways. As a result of this event, the activation of mitogen-activated protein kinase (MEK/MAPKK) takes place, which increases the expression of the genes promoting cell proliferation and survival [39]. Brain tumours of low malignancy (grade I and II malignancy according to the WHO classification) show a moderate level of chemokine SDF-1 expression and CXCR4 receptor, while the malignant glioma of grade IV malignancy presents with a high level of expression, predominantly in the perivascular and necrotic regions $[13,39]$. Based on the clinical data, the patients with CXCR4-positive glioblastoma showed worse post-surgery prognosis as compared to CXCR4-negative ones [13]. It has been also determined that CXCR4 positivity correlates with the size of glioma while it does not correlate with patients' age and gender [13,97].

\section{PIM kinases}

PIM1 and PIM3 belong to the serine-threonine kinases, involved in the cell survival, proliferation and the cell cycle regulation. PIM induces the release of antiapoptotic proteins $\mathrm{BCL}-\mathrm{XL} / \mathrm{BCL}-2$, which in turn may contribute to tumour development.

Overexpression of the kinases of the PIM family takes place in many neoplastic processes including glioma, leukaemia, lymphoma, and colon cancer $[78,88,102,111]$. The studies of Quan and collaborators proved that a decrease in the PIM3 activity causes a reduction in the glioma cell proliferation and an increase in the extent of apoptosis [88]. In addition, the interaction between PIM1 and the Myc oncogene may enhance tumour proliferation and aggressiveness. Moreover, it has been shown that this kinase significantly decreases the sensitivity of neoplastic cells to the applied chemotherapy, among others through the activation of membrane transporters expelling drugs outside the cell, and through the blockade of binding sites for apoptosis activators (e.g. p53-Etk) [114]. As PIM1 is regulated by interleukins, there is a possibility of blocking its activity by means of immunotherapy with specific antibodies, e.g. monoclonal P9 antibody [114]. Also, studies of PIM1 selective inhibitors for anti-cancer action, including AZD1208 or SGI-1776 compounds, are at the stage of preclinical research [128].

\section{Receptor tyrosine kinases}

\section{IGR-1R and IR}

IGR-1R and IR are transmembrane receptors with tyrosine kinase activity, and highly homologous structure. They are heterotetramers built of pairs of extracellular $\alpha$ subunits and transmembrane $\beta$ subunits, connected with disulfide bonds. Binding of ligands to $\alpha$ subunits results in the autophosphorylation of $\beta$ subunits and receptor activation [35]. It has been observed that in many types of neoplastic cells including GBM cells, the overexpression of IGF-1R takes place, which is in favour of proliferation, 
differentiation, invasiveness and survivability of tumour cells [14].

A decrease in the activity of IGF-1R leads to the apoptosis of tumour cells. Moreover, the increase in its expression is associated with the enhancement of resistance of tumour cells, including those of gliomas, to radio- and chemotherapy (e.g. temozolomide). For this reason IGF-1R has been considered as an attractive target for developing anti-cancer therapies, while determining its expression level could allow to select patients susceptible to such treatment [109]. The therapy targeting IGF-1R is based on the use of monoclonal neutralizing antibodies and small molecule inhibitors of its tyrosine kinase activity [5]. IGF-1R tyrosine kinase inhibitors PQ401, GSK1838705A, AXL1717 and NVP-AEW541 have all shown pre-clinically promising results as to their anti-glioma activity [85].

Insulin receptor (IR), similarly to IGF-1R, belongs to receptor tyrosine kinases and may play a key role in the processes of neoplastic transformation $[8,17,55]$. Two isoforms of the insulin receptor can be distinguished: shorter IR-A and longer IR-B, which are distinct in regard to the $\alpha$ subunit structure and capability of ligand binding [117]. Both isoforms may bind insulin and thereby regulate cell metabolism via the PI3K/AKT pathway. In addition, IR-A shows a high affinity to IGF-2, what is in favour of tumour development and metastasis formation. The mitogenic pathway leads through the RAS/RAF/MEK/ERK signalling cascade. It has been demonstrated that the inhibition of the IR action results in a decrease in tumour cell proliferation, and alleviates disturbances in the formation of blood and lymphatic vessels [127]. Equally important, a decrease in IR expression also results in the increase of the of sensitivity of tumours to therapies directed against IGF-1R [115].

\section{Other receptor tyrosine kinases}

Quite recently a new light has been shed on the tumorigenic role of anaplastic lymphoma kinase (ALK) for brain tumours. ALK is a receptor tyrosine kinase in the insulin receptor superfamily [121]. ALK is highly expressed among others in glioblastomas and WNT-activated medulloblastomas in paediatric populations, where it has been recommended as a valuable marker in routine investigations [56]. Hence, ALK inhibitors (alectinib) might be considered for treatment of selected brain tumours [11].
Platelet-derived growth factor (PDGF) and the fibroblast growth factor receptors (FGFRs) have been also implicated in glioma progression. PDGF expression correlates with poor glioblastoma prognosis and can be involved in the conversion of low- to highgrade gliomas [20]. Imatinib inhibits PDGF and other selected tyrosine kinases, however, it has very limited therapeutic efficacy towards glioblastoma $[36,98]$. Although trials using PDGFR kinase inhibitors have been largely disappointing [62], new attempts of the improved targeting PDGFR $\alpha$ signalling upon pre-clinical studies are still awaited. In turn, FGFR genomic alterations are rare in glioblastoma, however FGFR signalling may also have an impact on malignant glioma progression through activation of mitogenic, migratory, and antiapoptotic responses. Moreover, FGFR signalling inhibition may target tumour vascularization [51]. Studies of small-molecule inhibitors of FGFR tyrosine kinases are underway, which hopefully will boost the research of FGFR inhibition for glioblastoma treatment as well [47].

Likewise, dysregulated receptor tyrosine kinase MET - mesenchymal-epithelial transition factor, and its ligand hepatocyte growth factor (HGF) may have pivotal roles in the progression of gliomas [24]. Downstream mediators of MET signalling include Ras/ MAPK, PI3K/Akt, STAT, Cox-2/PGE2 and Wnt/ $\beta$-catenin pathways that regulate a variety of glioblastoma cell responses. The inhibitors of MET (Crizotinib, Volitinib, SGX523, INCB28060, Cabozantinib, Altiratinib, CM-118, Brefelamide and PLB-1001), although promising in preclinical anti-glioma research brought very modest clinical benefits or have not been clinically tested. It has been postulated that only selected groups of patients might benefit from this therapeutic approach, possibly in combination with other anticancer agents [24]. Inadequate response of GBM cells to MET (and EGFR) inhibition may result from bypass signalling e.g. via FGFR-SPRY2 that also needs to be blocked for the therapeutic effect to overcome the drug resistance [32].

\section{Non-receptor tyrosine kinases}

Non-receptor tyrosine kinases (nRTKs) are cytosolic enzymes classically involved in the signal transduction within the immune system. Their role in glial tumours may rely on regulating cell survival, division/propagation and adhesion, gene expression, immune response and tumorigenesis, especially considering their oncogenic variants [104]. New 
developments include the use of inhibition of Janus kinase 2 (JAK2) of the Janus kinase family for the treatment of glioma. JAK is associated with cytokine receptors and activates signal transducers and activators of transcription (STATs). JAK2 inhibitor ruxolitinib (Jakavi) has been approved for the treatment of myelofibrosis and polycythaemia vera [89]. Currently ruxolitinib combined with temozolomide and radiation therapy is investigated for Grade III gliomas and glioblastoma (NCT03514069). Preclinical research showed that treatment with ruxolitinib decreased the U87 malignant glioma cells invasiveness and tumorigenesis [33].

Noteworthy, another non-receptor tyrosine kinase SRC actively sustains tumour growth, hence SRC inhibition has become subject to scrupulous research lately. Many RTKs downstream signalling pathways converge on SRC, involved in cell survival, adhesion, proliferation, motility, and angiogenesis [26]. Unfortunately, small molecule SRC tyrosine kinase inhibitors such as dasatinib, bosutinib, saracatinib, and ponatinib brought no promising effect for GBM. However, it has been suggested that other inhibitors of SRC kinase (PP2, SI221, SU6656) can be considered for GBM treatment, though mostly based on preclinical research. In this regard the poor permeability of the BBB of SRC-targeting drugs remains an open concern [26].

\section{Protein kinase D}

Protein kinase D1, initially described as the atypical PKC $\mu$ and regarded as a member of the protein kinase C (PKC) family, later was classed amongst a new subgroup of PKD family belonging to the group of calcium/calmodulin-dependent kinases [94]. The PKD family comprises three kinases that are homologous regarding their structure and function: PKD1, PKD2 and PKD3, which are responsible for cell proliferation and differentiation [94,95]. The gene for PKD1, also known as PRKD1, is localized on chromosome $14 q 11$. PKD1 is widely distributed in many human organs, including thyroid, brain, heart and lungs. Amongst the PKD family, PKD1 has the greatest molecular weight of $115 \mathrm{kDa}$ and is involved in many biological functions in normal and pathological conditions $[57,94]$.

PKD1 is mainly localized in the cytoplasm and, in a small portion, in the Golgi apparatus and mitochondria. This kinase regulates the processes associated with cell survival, proliferation, mobility and apopto- sis, and is responsible for angiogenesis and oncogenesis $[44,106,116]$. The activity of PKD1 may increase and be a subject to modulation by a variety of factors, including neuropeptides, tumour necrosis factor (TNF) or PDGF. Furthermore, studies have shown that G-protein coupled receptors (GPCR) also may mediate the PKD1 activation [23]. The regulation of the PKD1 is mediated by different mechanisms, among others with the involvement of PKC signalling. At the first step, the activation of surface receptor takes place due to different stimuli, while the last step is the activation of PKD1 by PKC $[94,110]$. PKD1 as a downstream component of the PKC pathway takes part in the activation of mitogen-activated protein kinase kinase/extracellular signal-regulated kinase (MEK/ERK) signalling pathways [23]. ERK1/2 and Akt/ protein kinase $B$ signalling pathways play a dominant role in the regulation of gene expression and inhibition of apoptosis [68,69]. PKD is widely involved in molecular biological processes that regulate the proliferation and invasion of neoplastic cells, however the knowledge on PKD expression and function in primary glial brain tumours is still limited [103]. Its isoforms, PKD2 and PKD3, enhance the invasiveness of tumour cells. It has been demonstrated that the silencing of the PKD2 activity decreases the migration of glioblastoma cells in vitro [12]. In the tumours of glial origin, including glioblastoma, the expression of kinases from the PKD family (PKD1, PKD2, PKD3) is enhanced and depends upon the degree of tumour malignancy, while their inhibition decreases GBM cell proliferation [7]. Recent studies have shown that isothiourea derivatives were found to inhibit the signalling activity of PKD1 in glial cell lines [86], associated with the increased extent of tumour cell death.

Interestingly, it has been demonstrated that isoforms of PKD are being further activated in the hypoxic conditions, which may relate to the resistance of tumour cells to the investigated PKD1 inhibitors upon tumour hypoxia [6]. In such scenario the modulation of tumour oxygenation appears to be a justified approach for increasing the effectiveness of investigated anticancer agents $[107,126]$.

\section{Nek2A}

Serine/threonine-protein kinase NEK2A is an abbreviated name for $A$ isoform of the never in mitosis (NIMA) related kinase 2 A, playing an important role in the regulation of cell division, including the duplication of centrosome, the organization and 
stabilization of microtubules, kinetochore assembly, the organization of mitotic spindle, chromatin condensation, alignment of chromosomes and mRNA splicing $[41,124]$. NEK2A also enhances the immunologic responses through the stimulation of $B$ lymphocytes production. NEK2A is built of the N-terminal catalytic domain and $\mathrm{C}$-terminal regulatory domain, within which after dimerization several transautophosphorylations take place, regulating the activity of this kinase. The level of NEK2A changes depending on the cell cycle phase: it is low in $G 1$, next it rises in $\mathrm{S}$ and $\mathrm{G} 2$ phases, only to abruptly decrease as a result of ubiquitination and proteasomal degradation at the beginning of the cell division phase [41]. NEK2A activity can be inhibited also by p53 or protein phosphatase-1 (PP1) that dephosphorylates NEK2A while the latter can be activated as a result of the action of FoxM1 transcription factor, as well as PLK1 and CDK4. In turn, NEK2A by itself regulates the action of mitotic proteins (e.g. Hec1, MAD1, MAD2), TRG-1, $\beta$-catenin and SRSF1, and thereby a large portion of processes upon cell divisions. In many tumour types, including glioblastoma, the increased level of NEK2A was noted, what constitutes a negative prognostic factor $[41,120]$. NEK2A overexpression may cause chromosomal instability, thereby it promotes the origin and progression of tumours, cell proliferation and metastasis formation [21,124]. In addition, it contributes to the attenuation of apoptosis and the formation of resistance towards chemotherapy, mostly via the activation of cell membrane pumps participating in driving anticancer drugs out of the cell and their clearance from the system [130]. Due to this, the inhibition of NEK2A activity appears to be an attractive goal for new therapeutic strategies. One of the isothiourea derivatives has been found to inhibit NEK2A, as determined with the kinase activity panel investigations [54]. Interestingly, NEK2A has been suggested to be responsible for glioma stem cells (GSC) maintenance, whereas NEK2A inhibitor CMP3a attenuated GBM growth in a mouse model [119]. Although these data clearly suggest the role of NEK2 in GCS clonogenicity, further research is needed to establish NEK2 as a clinically relevant molecular target in GBM.

\section{Future directions and conclusions}

In the cells of primary CNS tumours of glial origin, altered expression and signalling activity of many kinases have been revealed. Therefore, kinase inhibition, including new pentabromobenzyl-isothiourea derivatives for CK2 inhibition, appears to be a justified and promising research direction for novel anti-glioma therapies. Cancer stem cells can be also targeted with this approach, although further research is needed to explore this opportunity. Apart from researching inhibitors of angiogenic signals, DNA repair and modulators of tumour immune responses, the efforts should continue to develop novel small molecule inhibitors of oncogenic protein kinases for anti-glioma therapy.

\section{Acknowledgements}

The research was supported by the Foundation for the Development of Diagnostics and Therapy, Warsaw.

\section{Disclosure}

The authors report no conflict of interest.

\section{References}

1. Akhavan D, Cloughesy TF, Mischel PS. mTOR signaling in glioblastoma: lessons learned from bench to bedside. Neuro Oncol 2010; 12: 882-889.

2. Aldape K, Zadeh G, Mansouri S, Reifenberger G, von Deimling A. Glioblastoma: pathology, molecular mechanisms and markers. Acta Neuropathol 2015; 129: 829-848.

3. Aldape KD, Okcu MF, Bondy ML, Wrensch M. Molecular epidemiology of glioblastoma. Cancer J 2003; 9: 99-106.

4. Appin CL, Brat DJ. Biomarker-driven diagnosis of diffuse gliomas. Mol Aspects Med 2015; 45: 87-96.

5. Arcaro A. Targeting the insulin-like growth factor-1 receptor in human cancer. Front Pharmacol 2013; 4: 30.

6. Azoitei N, Pusapati GV, Kleger A, Möller P, Küfer R, Genze F, Wagner M, van Lint J, Carmeliet P, Adler G, Seufferlein T. Protein kinase D2 is a crucial regulator of tumour cell-endothelial cell communication in gastrointestinal tumours. Gut 2010; 59: 1316-1330.

7. Azoitei N, Kleger A, Schoo N, Thal DR, Brunner C, Pusapati GV, Filatova A, Genze F, Möller P, Acker T, Kuefer R, van Lint J, Baust H, Adler G, Seufferlein T. Protein kinase D2 is a novel regulator of glioblastoma growth and tumor formation. Neuro Oncol 2011; 13: 710-724.

8. Baserga R, Peruzzi F, Reiss K. The IGF-1 receptor in cancer biology. Int J Cancer 2003; 107: 873-877.

9. Becher OJ, Gilheeney SW, Khakoo Y, Lyden DC, Haque S, De Braganca KC, Kolesar JM, Huse JT, Modak S, Wexler LH, Kramer K, Spasojevic I, Dunkel IJ. A phase I study of perifosine with temsirolimus for recurrent pediatric solid tumors. Pediatr Blood Cancer 2017; 64.

10. Benjamin R, Capparella J, Brown A. Classification of glioblastoma multiforme in adults by molecular genetics. Cancer I 2003; 9: 82-90. 
11. Berberich A, Schmitt LM, Pusch S, Hielscher T, Rübmann P Hucke N, Latzer P, Heßling B, Lemke D, Kessler T, Platten M, Wick W. cMyc and ERK activity are associated with resistance to ALK inhibitory treatment in glioblastoma. J Neurooncol 2020; 146: 9-23.

12. Bernhart E, Damm S, Wintersperger A, DeVaney T, Zimmer A, Raynham T, Ireson C, Sattler W. Protein kinase D2 regulates migration and invasion of U87MG glioblastoma cells in vitro. Exp Cell Res 2013; 319: 2037-2048.

13. Bian XW, Yang SX, Chen JH, Ping YF, Zhou XD, Wang QL, Jiang XF, Gong W, Xiao HL, Du LL, Chen ZG, Zhao W, Shi JG, Wang JM. Preferential expression of chemokine receptor CXCR4 by highly malignant human gliomas and its association with poor patient survival. Neurosurgery 2007; 61: 570578; discussion 578-579.

14. Bielen A, Perryman L, Box GM, Valenti M, de Haven Brandon A, Martins V, Jury A, Popov S, Gowan S, Jeay S, Raynaud FI, Hofmann F, Hargrave D, Eccles SA, Jones C. Enhanced efficacy of IGF1R inhibition in pediatric glioblastoma by combinatorial targeting of PDGFR $\alpha / \beta$. Mol Cancer Ther 2011; 10: 1407-1418.

15. Bongaarts A, van Scheppingen J, Korotkov A, Mijnsbergen C Anink JJ, Jansen FE, Spliet WGM, den Dunnen WFA, Gruber VE, Scholl T, Samueli S, Hainfellner JA, Feucht M, Kotulska K, Jozwiak S, Grajkowska W, Buccoliero AM, Caporalini C, Giordano F, Genitori L, Coras R, Blümcke I, Krsek P, Zamecnik J, Meijer L, Scicluna BP, Schouten-van Meeteren AYN, Mühlebner A, Mills JD, Aronica E. The coding and non-coding transcriptional landscape of subependymal giant cell astrocytomas. Brain 2020; 143: 131-149.

16. Bronner SM, Merrick KA, Murray J, Salphati L, Moffat JG, Pang J, Sneeringer CJ, Dompe N, Cyr P, Purkey H, de Leon Boenig G, Li J, Kolesnikov A, Larouche-Gauthier R, Wah Lai K, Shen X, AubertNicol S, Chen YC, Cheong J, Crawford JJ, Hafner M, Haghshenas P, Jakalian A, Leclerc JP, Lim NK, O'Brien T, Plise EG, Shalan H, Sturino C, Wai J, Xiao Y, Yin J, Zhao L, Gould S, Olivero A, Heffron TP. Design of a brain-penetrant CDK4/6 inhibitor for glioblastoma. Bioorg Med Chem Lett 2019; 29: 2294-2301.

17. Buck E, Mulvihill M. Small molecule inhibitors of the IGF-1R/ IR axis for the treatment of cancer. Expert Opin Investig Drugs 2011; 20: 605-621.

18. Burris HA, $3^{\text {rd }}$. Overcoming acquired resistance to anticancer therapy: focus on the PI3K/AKT/mTOR pathway. Cancer Chemother Pharmacol 2013; 71: 829-842.

19. Camara-Quintana JQ Nitta RT, Li G. Pathology: commonly monitored glioblastoma markers: EFGR, EGFRvIII, PTEN, and MGMT. Neurosurg Clin N Am 2012; 23: 237-246.

20. Cantanhede IG, de Oliveira JRM. PDGF family expression in glioblastoma multiforme: data compilation from ivy glioblastoma atlas project database. Sci Rep 2017; 7: 15271.

21. Cappello P, Blaser H, Gorrini C, Lin DC, Elia AJ, Wakeham A, Haider S, Boutros PC, Mason JM, Miller NA, Youngson B, Done SJ, Mak TW. Role of Nek2 on centrosome duplication and aneuploidy in breast cancer cells. Oncogene 2014; 33 2375-2384

22. Carrasco-Garcia E, Saceda M, Martinez-Lacaci I. Role of receptor tyrosine kinases and their ligands in glioblastoma. Cells 2014; 3: 199-235.
23. Chen SX, Hu CL, Liao YH, Zhao WJ. L1 modulates PKD1 phosphorylation in cerebellar granule neurons. Neurosci Lett 2015; 584: 331-336.

24. Cheng F, Guo D. MET in glioma: signaling pathways and targeted therapies. J Exp Clin Cancer Res 2019; 38: 270.

25. Chou ST, Patil R, Galstyan A, Gangalum PR, Cavenee WK, Furnari FB, Ljubimov VA, Chesnokova A, Kramerov AA, Ding H, Falahatian V, Mashouf L, Fox I, Black KL, Holler E, Ljubimov AV, Ljubimova JY. Simultaneous blockade of interacting CK2 and EGFR pathways by tumor-targeting nanobioconjugates increases therapeutic efficacy against glioblastoma multiforme. J Control Release 2016; 244: 14-23.

26. Cirotti C, Contadini C, Barilà D. SRC kinase in glioblastoma news from an old acquaintance. Cancers (Basel) 2020; 12: 1558.

27. Cloughesy TF, Cavenee WK, Mischel PS. Glioblastoma: from molecular pathology to targeted treatment. Annu Rev Pathol 2014; 9: 1-25.

28. Cozza G, Pinna LA, Moro S. Protein kinase CK2 inhibitors: a patent review. Expert Opin Ther Pat 2012; 22: 1081-1097.

29. Cozza G, Sarno S, Ruzzene M, Girardi C, Orzeszko A, Kazimierczuk Z, Zagotto G, Bonaiuto E, Di Paolo ML, Pinna LA. Exploiting the repertoire of CK2 inhibitors to target DYRK and PIM kinases. Biochim Biophys Acta 2013; 1834: 1402-1409.

30. Cozza G, Girardi C, Ranchio A, Lolli G, Sarno S, Orzeszko A, Kazimierczuk Z, Battistutta R, Ruzzene M, Pinna LA. Cell-permeable dual inhibitors of protein kinases CK2 and PIM-1: structural features and pharmacological potential. Cell Mol Life Sci 2014; 71: 3173-3185.

31. Dabora SL, Jozwiak S, Franz DN, Roberts PS, Nieto A, Chung J, Choy YS, Reeve MP, Thiele E, Egelhoff JC, Kasprzyk-Obara J, Domanska-Pakiela D, Kwiatkowski DJ. Mutational analysis in a cohort of 224 tuberous sclerosis patients indicates increased severity of TSC2, compared with TSC1, disease in multiple organs. Am J Hum Genet 2001; 68: 64-80.

32. Day EK, Sosale NG, Xiao A, Zhong Q, Purow B, Lazzara MJ. Glioblastoma cell resistance to EGFR and MET inhibition can be overcome via blockade of FGFR-SPRY2 bypass signaling. Cell Rep 2020; 30: 3383-3396.e3387.

33. Delen E, Doğanlar O. The dose dependent effects of ruxolitinib on the invasion and tumorigenesis in gliomas cells via inhibition of interferon gamma-depended JAK/STAT signaling pathway. J Korean Neurosurg Soc 2020; 63: 444-454.

34. Demuth T, Reavie LB, Rennert JL, Nakada M, Nakada S, Hoelzinger DB, Beaudry CE, Henrichs AN, Anderson EM, Berens ME. MAP-ing glioma invasion: Mitogen-activated protein kinase kinase 3 and p38 drive glioma invasion and progression and predict patient survival. Mol Cancer Ther 2007; 6: 1212.

35. Denduluri SK, Idowu O, Wang Z, Liao Z, Yan Z, Mohammed MK, Ye J, Wei Q, Wang J, Zhao L, Luu HH. Insulin-like growth factor (IGF) signaling in tumorigenesis and the development of cancer drug resistance. Genes Dis 2015; 2: 13-25.

36. Dresemann G. Imatinib and hydroxyurea in pretreated progressive glioblastoma multiforme: a patient series. Ann Oncol 2005; 16: 1702-1708. 
37. Duong-Ly KC, Peterson JR. The human kinome and kinase inhibition. Current protocols in pharmacology 2013; Chapter 2 Unit 2.9.

38. Ebrahimi-Fakhari D, Franz DN. Pharmacological treatment strategies for subependymal giant cell astrocytoma (SEGA). Expert Opin Pharmacother 2020; 21: 1329-1336.

39. Ehtesham M, Winston JA, Kabos P, Thompson RC. CXCR4 expression mediates glioma cell invasiveness. Oncogene 2006; 25: 2801-2806.

40. Engelman JA, Luo J, Cantley LC. The evolution of phosphatidy linositol 3-kinases as regulators of growth and metabolism. Nat Rev Genet 2006; 7: 606-619.

41. Fang Y, Zhang X. Targeting NEK2 as a promising therapeutic approach for cancer treatment. Cell Cycle 2016; 15: 895-907.

42. Fensterle J, Aicher B, Seipelt I, Teifel M, Engel J. Current view on the mechanism of action of perifosine in cancer. Anticancer Agents Med Chem 2014; 14: 629-635.

43. Frassanito P, Noya C, Tamburrini G. Current trends in the management of subependymal giant cell astrocytomas in tuberous sclerosis. Childs Nerv Syst 2020; 36: 2527-2536.

44. Guha S, Tanasanvimon S, Sinnett-Smith J, Rozengurt E. Role of protein kinase D signaling in pancreatic cancer. Biochem Pharmacol 2010; 80: 1946-1954.

45. Inoki K, Li Y, Xu T, Guan KL. Rheb GTPase is a direct target of TSC2 GAP activity and regulates mTOR signaling. Genes Dev 2003; 17: 1829-1834.

46. Jhanwar-Uniyal M, Labagnara M, Friedman M, Kwasnicki A, Murali R. Glioblastoma: molecular pathways, stem cells and therapeutic targets. Cancers (Basel) 2015; 7: 538-555.

47. Jimenez-Pascual A, Siebzehnrubl FA. Fibroblast growth factor receptor functions in glioblastoma. Cells 2019; 8: 715.

48. Jozwiak S, Mandera M, Mlynarski W. Natural history and current treatment options for subependymal giant cell astrocytoma in tuberous sclerosis complex. Semin Pediatr Neurol 2015 22: 274-281.

49. Kaminska B, Ellert-Miklaszewska A, Oberbek A, Wisniewski P, Kaza B, Makowska M, Bretner M, Kazimierczuk Z. Efficacy and mechanism of anti-tumor action of new potential CK2 inhibitors toward glioblastoma cells. Int J Oncol 2009; 35: 1091 1100.

50. Kannaiyan R, Mahadevan D. A comprehensive review of protein kinase inhibitors for cancer therapy. Expert Rev Anticancer Ther 2018; 18: 1249-1270.

51. Katoh M, Nakagama H. FGF receptors: cancer biology and therapeutics. Med Res Rev 2014; 34: 280-300.

52. Kim A, Cohen MS. The discovery of vemurafenib for the treat ment of BRAF-mutated metastatic melanoma. Expert Opin Drug Discov 2016; 11: 907-916.

53. Kim G, Ko YT. Small molecule tyrosine kinase inhibitors in glioblastoma. Arch Pharm Res 2020; 43: 385-394.

54. Koronkiewicz M, Kazimierczuk Z, Szarpak K, Chilmonczyk Z. Proapoptotic effects of new pentabromobenzylisothiouronium salts in a human prostate adenocarcinoma cell line. Acta Pol Pharm 2012; 69: 1325-1333.

55. Koronkiewicz M, Chilmonczyk Z, Kazimierczuk Z. Synergistic anti-leukemic effects of CK2 inhibitors and pentabromobenzylisothioureas in vitro. Anticancer Res 2013; 33: 4891-4899.
56. Łastowska M, Trubicka J, Karkucińska-Więckowska A, Kaleta M, Tarasińska M, Perek-Polnik M, Sobocińska AA, Dembowska-Bagińska B, Grajkowska W, Matyja E. Immunohistochemical detection of ALK protein identifies APC mutated medulloblastoma and differentiates the WNT-activated medulloblastoma from other types of posterior fossa childhood tumors. Brain Tumor Pathol 2019; 36: 1-6.

57. LaValle CR, George KM, Sharlow ER, Lazo JS, Wipf P, Wang QJ. Protein kinase D as a potential new target for cancer therapy. Biochim Biophys Acta 2010; 1806: 183-192.

58. Leung AK, Robson WL. Tuberous sclerosis complex: a review. J Pediatr Health Care 2007; 21: 108-114.

59. Li Z, Du L, Li C, Wu W. Human chorionic gonadotropin $\beta$ induces cell motility via ERK1/2 and MMP-2 activation in human glioblastoma U87MG cells. J Neurooncol 2013; 111: 237-244.

60. Lin KY, Tai C, Hsu JC, Li CF, Fang CL, Lai HC, Hseu YC, Lin YF, Uen $\mathrm{YH}$. Overexpression of nuclear protein kinase CK2 alpha catalytic subunit (CK2alpha) as a poor prognosticator in human colorectal cancer. PLoS One 2011; 6: e17193.

61. Linden MA, Lopez KT, Fletcher JA, Morris EM, Meers GM, Siddique S, Laughlin MH, Sowers JR, Thyfault JP, Ibdah JA, Rector RS. Combining metformin therapy with caloric restriction for the management of type 2 diabetes and nonalcoholic fatty liver disease in obese rats. Appl Physiol Nutr Metab 2015; 40: 1038-1047.

62. Liu KW, Hu B, Cheng SY. Platelet-derived growth factor receptor alpha in glioma: a bad seed. Chin J Cancer 2011; 30: 590602.

63. Louis DN, Ohgaki H, Wiestler OD, Cavenee WK, Burger PC, Jouvet A, Scheithauer BW, Kleihues P. The 2007 WHO classification of tumours of the central nervous system. Acta Neuropathol 2007; 114: 97-109.

64. Lovly CM, Iyengar P, Gainor JF. Managing resistance to EFGRand ALK-targeted therapies. Am Soc Clin Oncol Educ Book 2017; 37: 607-618.

65. Mahoney SJ, Narayan S, Molz L, Berstler LA, Kang SA, Vlasuk GP, Saiah E. A small molecule inhibitor of Rheb selectively targets mTORC1 signaling. Nat Commun 2018; 9: 548.

66. Malzkorn B, Reifenberger G. Integrated diagnostics of diffuse astrocytic and oligodendroglial tumors. Pathologe 2019; 40: 9-17.

67. Matsuda KI, Sato A, Okada M, Shibuya K, Seino S, Suzuki K, Watanabe E, Narita Y, Shibui S, Kayama T, Kitanaka C. Targeting JNK for therapeutic depletion of stem-like glioblastoma cells. Sci Rep 2012; 2: 516.

68. McCubrey JA, Steelman LS, Abrams SL, Lee JT, Chang F, Bertrand FE, Navolanic PM, Terrian DM, Franklin RA, D'Assoro AB, Salisbury JL, Mazzarino MC, Stivala F, Libra M. Roles of the RAF/MEK/ERK and PI3K/PTEN/AKT pathways in malignant transformation and drug resistance. Adv Enzyme Regul 2006; 46: 249-279.

69. McCubrey JA, Steelman LS, Chappell WH, Abrams SL, Wong EW, Chang F, Lehmann B, Terrian DM, Milella M, Tafuri A, Stivala F, Libra M, Basecke J, Evangelisti C, Martelli AM, Franklin RA. Roles of the Raf/MEK/ERK pathway in cell growth, malignant transformation and drug resistance. Biochim Biophys Acta 2007; 1773: 1263-1284. 
70. Miller MA, Sullivan RJ, Lauffenburger DA. Molecular pathways: receptor ectodomain shedding in treatment, resistance, and monitoring of cancer. Clin Cancer Res 2017; 23: 623-629.

71. Miller TW, Traphagen NA, Li J, Lewis LD, Lopes B, Asthagiri A, Loomba J, De Jong J, Schiff D, Patel SH, Purow BW, Fadul CE. Tumor pharmacokinetics and pharmacodynamics of the CDK4/6 inhibitor ribociclib in patients with recurrent glioblastoma. J Neurooncol 2019; 144: 563-572.

72. Montano N, D’Alessandris QG, Izzo A, Fernandez E, Pallini R. Biomarkers for glioblastoma multiforme: status quo. J Clin Transl Res 2016; 2: 3-10.

73. Montemurro N. Glioblastoma multiforme and genetic mutations: the issue is not over yet. An overview of the current literature. J Neurol Surg A Cent Eur Neurosurg 2020; 81: 64-70.

74. Moucadel V, Prudent R, Sautel CF, Teillet F, Barette C, Lafanechere L, Receveur-Brechot V, Cochet C. Antitumoral activity of allosteric inhibitors of protein kinase CK2. Oncotarget 2011; 2: 997-1010.

75. Najda-Bernatowicz A, Lebska M, Orzeszko A, Kopanska K, Krzywinska E, Muszynska G, Bretner M. Synthesis of new analogs of benzotriazole, benzimidazole and phthalimide potential inhibitors of human protein kinase CK2. Bioorg Med Chem 2009; 17: 1573-1578.

76. Nakada M, Kita D, Watanabe T, Hayashi Y, Teng L, Pyko IV, Hamada J. Aberrant signaling pathways in glioma. Cancers (Basel) 2011; 3: 3242-3278.

77. Nakamura JL, Garcia E, Pieper RO. S6K1 plays a key role in glial transformation. Cancer Res 2008; 68: 6516-6523.

78. Nawijn MC, Alendar A, Berns A. For better or for worse: the role of Pim oncogenes in tumorigenesis. Nat Rev Cancer 2011; 11: 23-34.

79. Ohgaki $\mathrm{H}$, Kleihues $\mathrm{P}$. The definition of primary and secondary glioblastoma. Clin Cancer Res 2013; 19: 764-772.

80. Olmez I, Zhang Y, Manigat L, Benamar M, Brenneman B, Nakano I, Godlewski J, Bronisz A, Lee J, Abbas T, Abounader R, Purow B. Combined c-Met/Trk inhibition overcomes resistance to CDK4/6 inhibitors in glioblastoma. Cancer Res 2018; 78: 4360-4369.

81. Olsen BB, Svenstrup TH, Guerra B. Downregulation of protein kinase CK2 induces autophagic cell death through modulation of the mTOR and MAPK signaling pathways in human glioblastoma cells. Int J Oncol 2012; 41: 1967-1976.

82. Ouyang T, Zhang N, Benjamin T, Wang L, Jiao J, Zhao Y, Chen J. Subependymal giant cell astrocytoma: current concepts, management, and future directions. Childs Nerv Syst 2014; 30: 561-570.

83. Pachow D, Wick W, Gutmann DH, Mawrin C. The mTOR signaling pathway as a treatment target for intracranial neoplasms. Neuro Oncol 2015; 17: 189-199.

84. Pagano MA, Bain J, Kazimierczuk Z, Sarno S, Ruzzene M, Di Maira G, Elliott M, Orzeszko A, Cozza G, Meggio F, Pinna LA. The selectivity of inhibitors of protein kinase CK2: an update. Biochem J 2008; 415: 353-365.

85. Pearson JRD, Regad T. Targeting cellular pathways in glioblas toma multiforme. Signal Transduct Target Ther 2017; 2: 17040.

86. Pucko E, Matyja E, Koronkiewicz M, Ostrowski RP, Kazimierczuk Z. Potent antitumour effects of novel pentabromoben- zylisothioureas studied on human glial-derived tumour cell lines. Anticancer Res 2018; 38: 2691-2705.

87. Pucko E, Ostrowski R, Matyja E. Novel small molecule protein kinase CK2 inhibitors exert potent antitumor effects on T98G and SEGA cells in vitro. Folia Neuropathol 2019; 57: 239-248.

88. Quan J, Zhou L, Qu J. Knockdown of Pim-3 suppresses the tumorigenicity of glioblastoma by regulating cell cycle and apoptosis. Cell Mol Biol (Noisy-le-grand) 2015; 61: 42-50.

89. Raedler LA. Jakafi (Ruxolitinib): First FDA-approved medication for the treatment of patients with polycythemia vera. Am Health Drug Benefits 2015; 8: 75-79.

90. Ramaswamy P, Nanjaiah ND, Borkotokey M. Role of MEK-ERK signaling mediated adhesion of glioma cells to extra-cellular matrix: Possible implication on migration and proliferation. Ann Neurosci 2019; 26: 52-56.

91. Raub TJ, Wishart GN, Kulanthaivel P, Staton BA, Ajamie RT, Sawada GA, Gelbert LM, Shannon HE, Sanchez-Martinez C, De Dios A. Brain exposure of two selective dual CDK4 and CDK6 inhibitors and the antitumor activity of CDK4 and CDK6 inhibition in combination with temozolomide in an intracranial glioblastoma xenograft. Drug Metab Dispos 2015; 43: 1360-1371.

92. Riess C, Irmscher N, Salewski I, Strüder D, Classen CF, GroßeThie C, Junghanss C, Maletzki C. Cyclin-dependent kinase inhibitors in head and neck cancer and glioblastoma-backbone or add-on in immune-oncology? Cancer Metastasis Rev 2020.

93. Roth J, Roach ES, Bartels U, Jozwiak S, Koenig MK, Weiner HL, Franz DM, Wang HZ. Subependymal giant cell astrocytoma: diagnosis, screening, and treatment. Recommendations from the International Tuberous Sclerosis Complex Consensus Conference 2012. Pediatr Neurol 2013; 49: 439-444.

94. Rozengurt E, Rey O, Waldron RT. Protein kinase D signaling. J Biol Chem 2005; 280: 13205-13208.

95. Rykx A, De Kimpe L, Mikhalap S, Vantus T, Seufferlein T, Vandenheede JR, Van Lint J. Protein kinase D: a family affair. FEBS Lett 2003; 546: 81-86.

96. Sadowski K, Kotulska K, Schwartz RA, Jozwiak S. Systemic effects of treatment with mTOR inhibitors in tuberous sclerosis complex: a comprehensive review. J Eur Acad Dermatol Venereol 2016; 30: 586-594.

97. Salmaggi A, Gelati M, Pollo B, Frigerio S, Eoli M, Silvani A, Broggi G, Ciusani E, Croci D, Boiardi A, De Rossi M. CXCL12 in malignant glial tumors: a possible role in angiogenesis and cross-talk between endothelial and tumoral cells. J Neurooncol 2004; 67: 305-317.

98. Sautter L, Hofheinz R, Tuettenberg J, Grimm M, Vajkoczy P, Groden C, Schmieder K, Hochhaus A, Wenz F, Giordano FA. Open-label phase II evaluation of imatinib in primary inoperable or incompletely resected and recurrent glioblastoma. Oncology 2020; 98: 16-22.

99. Schettini F, De Santo I, Rea CG, De Placido P, Formisano L Giuliano M, Arpino G, De Laurentiis M, Puglisi F, De Placido S, Del Mastro L. CDK 4/6 inhibitors as single agent in advanced solid tumors. Front Oncol 2018; 8: 608-608.

100. Schreck KC, Grossman SA, Pratilas CA. BRAF mutations and the utility of RAF and MEK inhibitors in primary brain tumors. Cancers (Basel) 2019; 11: 1262. 
101. Schulte A, Liffers K, Kathagen A, Riethdorf S, Zapf S, Merlo A, Kolbe K, Westphal M, Lamszus K. Erlotinib resistance in EGFR-amplified glioblastoma cells is associated with upregulation of EGFRvIII and PI3Kp1108. Neuro Oncol 2013; 15: 1289-1301.

102. Selmi T, Martello A, Vignudelli T, Ferrari E, Grande A, Gemelli C, Salomoni P, Ferrari S, Zanocco-Marani T. ZFP36 expression impairs glioblastoma cell lines viability and invasiveness by targeting multiple signal transduction pathways. Cell Cycle 2012; 11: 1977-1987.

103. Shabelnik MY, Kovalevska LM, Yurchenko MY, Shlapatska LM, Rzepetsky Y, Sidorenko SP. Differential expression of PKD1 and PKD2 in gastric cancer and analysis of PKD1 and PKD2 function in the model system. Exp Oncol 2011; 33: 206-211.

104. Siveen KS, Prabhu KS, Achkar IW, Kuttikrishnan S, Shyam S, Khan AQ, Merhi M, Dermime S, Uddin S. Role of non receptor tyrosine kinases in hematological malignances and its targeting by natural products. Mol Cancer 2018; 17: 31.

105. Soeda A, Lathia J, Williams BJ, Wu Q, Gallagher J, Androutsellis-Theotokis A, Giles AJ, Yang C, Zhuang Z, Gilbert MR, Rich JN, Park DM. The p38 signaling pathway mediates quiescence of glioma stem cells by regulating epidermal growth factor receptor trafficking. Oncotarget 2017; 8: 33316-33328.

106. Steinberg SF. Regulation of protein kinase D1 activity. Mol Pharmacol 2012; 81: 284-291.

107. Stępień K, Ostrowski RP, Matyja E. Hyperbaric oxygen as an adjunctive therapy in treatment of malignancies, including brain tumours. Med Oncol 2016; 33: 101.

108. Sun H, Xu X, Wu X, Zhang X, Liu F, Jia J, Guo X, Huang J, Jiang Z, Feng T, Chu H, Zhou Y, Zhang S, Liu Z, You Q. Discovery and design of tricyclic scaffolds as protein kinase CK2 (CK2) inhibitors through a combination of shape-based virtual screening and structure-based molecular modification. J Chem Inf Model 2013; 53: 2093-2102.

109. Sun Y, Sun X, Shen B. Molecular imaging of IGF-1R in cancer. Mol Imaging 2017; 16: 1536012117736648-1536012117736648.

110. Sundram V, Chauhan SC, Jaggi M. Emerging roles of protein kinase D1 in cancer. Mol Cancer Res 2011; 9: 985-996.

111. Swords R, Kelly K, Carew J, Nawrocki S, Mahalingam D, Sarantopoulos J, Bearss D, Giles F. The Pim kinases: new targets for drug development. Curr Drug Targets 2011; 12: 2059-2066.

112. Taylor JW, Parikh M, Phillips JJ, James CD, Molinaro AM, Butowski NA, Clarke J, Oberheim-Bush NA, Chang SM, Berger MS, Prados M. Phase-2 trial of palbociclib in adult patients with recurrent RB1-positive glioblastoma. J Neurooncol 2018; 140: 477-483

113. Thorne AH, Zanca C, Furnari F. Epidermal growth factor receptor targeting and challenges in glioblastoma. Neuro Oncol 2016; 18: 914-918.

114. Tursynbay Y, Zhang J, Li Z, Tokay T, Zhumadilov Z, Wu D, Xie Y. Pim-1 kinase as cancer drug target: An update. Biomed Rep 2016; 4: 140-146.

115. Ulanet DB, Ludwig DL, Kahn CR, Hanahan D. Insulin receptor functionally enhances multistage tumor progression and conveys intrinsic resistance to IGF-1R targeted therapy. Proc Natl Acad Sci U S A 2010; 107: 10791-10798.

116. Van Lint J, Rykx A, Maeda Y, Vantus T, Sturany S, Malhotra V, Vandenheede JR, Seufferlein T. Protein kinase D: an intracel- lular traffic regulator on the move. Trends Cell Biol 2002; 12: 193-200.

117. Vigneri R, Goldfine ID, Frittitta L. Insulin, insulin receptors, and cancer. J Endocrinol Invest 2016; 39: 1365-1376.

118. Vo VA, Lee JW, Lee HJ, Chun W, Lim SY, Kim SS. Inhibition of JNK potentiates temozolomide-induced cytotoxicity in U87MG glioblastoma cells via suppression of Akt phosphorylation. Anticancer Res 2014; 34: 5509-5515.

119. Wang J, Cheng P, Pavlyukov MS, Yu H, Zhang Z, Kim SH, Minata M, Mohyeldin A, Xie W, Chen D, Goidts V, Frett B, Hu W, Li H, Shin YJ, Lee Y, Nam DH, Kornblum HI, Wang M, Nakano I. Targeting NEK2 attenuates glioblastoma growth and radioresistance by destabilizing histone methyltransferase $\mathrm{EZH} 2$. J Clin Invest 2020; 130: 6187.

120. Wang S, Li W, Liu N, Zhang F, Liu H, Liu F, Liu J, Zhang T, Niu Y. Nek2A contributes to tumorigenic growth and possibly functions as potential therapeutic target for human breast cancer. J Cell Biochem 2012; 113: 1904-1914.

121. Webb TR, Slavish J, George RE, Look AT, Xue L, Jiang Q, Cui X, Rentrop WB, Morris SW. Anaplastic lymphoma kinase: role in cancer pathogenesis and small-molecule inhibitor development for therapy. Expert Rev Anticancer Ther 2009; 9: 331-356.

122. Wong RA, Luo X, Lu M, An Z, Haas-Kogan DA, Phillips JJ, Shokat KM, Weiss WA, Fan QW. Cooperative blockade of PKC $\alpha$ and JAK2 drives apoptosis in glioblastoma. Cancer Res 2020; 80: 709-718.

123. Wu S, Zhou Y, Yang G, Tian H, Geng Y, Hu Y, Lin K, Wu W. Sulforaphane-cysteine induces apoptosis by sustained activation of ERK1/2 and caspase 3 in human glioblastoma U373MG and U87MG cells. Oncol Rep 2017; 37: 2829-2838.

124. Xia J, Franqui Machin R, Gu Z, Zhan F. Role of NEK2A in human cancer and its therapeutic potentials. Biomed Res Int 2015; 2015: 862461.

125. Zanin S, Borgo C, Girardi C, O’Brien SE, Miyata Y, Pinna LA, Donella-Deana A, Ruzzene M. Effects of the CK2 inhibitors CX-4945 and CX-5011 on drug-resistant cells. PLoS One 2012; 7: e49193.

126. Zembrzuska K, Ostrowski RP, Matyja E. Hyperbaric oxygen increases glioma cell sensitivity to antitumor treatment with a novel isothiourea derivative in vitro. Oncol Rep 2019; 41: 2703-2716.

127. Zhang H, Fagan DH, Zeng X, Freeman KT, Sachdev D, Yee D. Inhibition of cancer cell proliferation and metastasis by insulin receptor downregulation. Oncogene 2010; 29: 2517-2527.

128. Zhang X, Song M, Kundu JK, Lee MH, Liu ZZ. PIM kinase as an executional target in cancer. J Cancer Prev 2018; 23: 109-116.

129. Zhang X, Chen L, Dang WQ, Cao MF, Xiao JF, LV SQ, Jiang WJ, Yao XH, Lu HM, Miao JY, Wang Y, Yu SC, Ping YF, Liu XD, Cui YH, Zhang $X$, Bian XW. CCL8 secreted by tumor-associated macrophages promotes invasion and stemness of glioblastoma cells via ERK1/2 signaling. Lab Invest 2020; 100: 619-629.

130. Zhou W, Yang Y, Xia J, Wang $H$, Salama ME, Xiong $W, X u H$, Shetty S, Chen T, Zeng Z, Shi L, Zangari M, Miles R, Bearss D, Tricot G, Zhan F. NEK2 induces drug resistance mainly through activation of efflux drug pumps and is associated with poor prognosis in myeloma and other cancers. Cancer Cell 2013; 23: $48-62$ 